\title{
Comunicación
}

\section{PREVALENCIA DE LEPTOSPIROSIS BOVINA EN DOS LOCALIDADES DE PUNO EN ÉPOCA DE SECA Y DETERMINACIÓN DE FACTORES DE RIESGO}

\author{
Prevalence of Bovine Leptospirosis at Two Localities in Puno During the \\ Dry SEason and Determination of Risk Factors
}

Fiorella Arias Ch. ${ }^{1}$, Francisco Suárez A. ${ }^{1,2}$, Wilfredo Huanca L. ${ }^{3}$, Hermelinda Rivera G. ${ }^{4}$, José Camacho S. ${ }^{5}$, Teodosio Huanca M. ${ }^{6}$

\section{Resumen}

\begin{abstract}
La leptospirosis es una enfermedad zoonótica causada por una espiroqueta del género Leptospira, de distribución mundial que tiene gran impacto económico por las importantes pérdidas que ocasiona en la ganadería, sobre todo en la reproducción y la producción láctea, ya que tiene potencial abortivo y es causante de mortalidad neonatal, además de disminuir o anular la producción de leche. El objetivo del presente trabajo fue determinar la prevalencia de leptospirosis en bovinos en dos predios del departamento de Puno, Perú (Estación Experimental de ILLPA- INIA y Ganadería Cárdenas en la localidad de Mañazo), y su asociación con la época del año y las edad. Se recolectaron 116 muestras de sangre del total de animales de ambos predios, en la época seca. Los sueros se evaluaron mediante la Prueba de Aglutinación Microscópica (MAT) para la detección de anticuerpos, empleándose una batería de cuatro serovares (canicola, icterohaemorrhagiae, pomona y hardjo). Se obtuvo una prevalencia total de $2.6 \%$, del cual $1.3 \%$ correspondió a animales de ILLPA-INIA y 5.3\% a los animales de Mañazo. El serovar icterohaemorrhagiae fue el único prevalente con un nivel de anticuerpos de 1:200. Estos resultados sugieren una prevalencia baja de Leptospira sp en la época de seca en la zona estudiada.
\end{abstract}

Palabras clave: Leptospira sp, bovinos, MAT, seroprevalencia, anticuerpos

\footnotetext{
${ }^{1}$ Laboratorio de Medicina Veterinaria Preventiva, ${ }^{3}$ Laboratorio de Reproducción Animal, ${ }^{4}$ Laboratorio de Microbiología y Parasitología Veterinaria, ${ }^{5}$ Laboratorio de Zootecnia y Producción Agropecuaria, Facultad de Medicina Veterinaria, Universidad Nacional Mayor de San Marcos

${ }^{2}$ E-mail: francisco_suarez2001@hotmail.com

${ }^{6}$ Estación Experimental INIA-Puno
} 
Leptospirosis is a disease caused by a spirochet of the genus Leptospira. It is a world-wide zoonotic disease with a great economic impact because of the important losses that causes to livestock farmers, especially in terms of reproduction performance and milk yield loses. The objective of the study was to estimate the prevalence of leptospirosis in bovines in two farms in the department of Puno, Peru: the ILLPA-INIA Experimental Station and Cardenas farm at Mañazo and its association with season and age. One hundred and sixteen serum samples collected during the dry season were evaluated. Blood samples were collected to all animals in both farms. The Microscopic Agglutination Test (MAT) was used for the detection of antibodies through a set of four serovars (canicola, icterohaemorrhagiae, pomona, and hardjo). The total prevalence was $2.6 \%$ while $1.3 \%$ corresponded to animals at ILLPA-INIA and 5.3\% to animals at Mañazo. The icterohaemorrhagiae was the only prevalent serovar and the level of antibodies was 1:200. The results suggested a low prevalence of Leptospira sp. in the dry season in the area of study.

Key words: Leptospira sp., bovines, MAT, seroprevalence, antibodies

La leptospirosis es una enfermedad de gran impacto económico en la ganadería, en especial en bovinos, debido a las pérdidas que ocasiona a través de abortos, mortalidad perinatal, nacimiento de crías débiles, infertilidad y disminución de la producción láctea (Liceras de Hidalgo, 1982). Es además, una zoonosis donde el hombre es un hospedador accidental. Se le considera una enfermedad ocupacional dado que afecta a ganaderos, veterinarios, agricultores, y carniceros, entre otros, ya que se adquiere a través del contacto con animales reservorios o con ambientes contaminados con su orina (Faine, 1994; Vinetz, 2001).

Es una enfermedad de amplia distribución en el Perú y en el mundo (OIE, 2004), habiéndose encontrado anticuerpos contra Leptospira en humanos y animales de la mayor parte de los departamentos del país (Ministerio de Salud, 2000; Céspedes et al., 2006). En el bovino, la enfermedad presenta alta morbilidad, pudiendo llegar al $75 \%$, y una mortalidad de 5\% (Maulloux, 1975).

El presente estudio pretendió determinar la seroprevalencia de leptospirosis en dos predios de ganado bovino a fin de poder desarrollar planes de control y prevención. Se trabajó con el total de animales de la Estación Experimental del INIA, Puno ( $\mathrm{n}=$ 78), y de una ganadería particular en la localidad de Mañazo, Puno ( $n=38)$. Los animales tenían edades comprendidas entre los tres meses y los ocho años, de procedencia local, y mayormente de la raza Brown Swiss. En ambos casos, el tipo de explotación era extensiva, con alimentación en base a pasturas, y el agua de bebida de acequias y riachuelos.

Las muestras de sangre se colectaron entre agosto y setiembre de 2005, que corresponde a la parte final de la época seca. La temperatura media en esa época es de $-5^{\circ} \mathrm{C}$, pudiendo haber zonas donde llega a $-10^{\circ} \mathrm{C}$ (Miranda, 1998). La sangre se extrajo de la vena de la cola utilizando el sistema de vacutainers ${ }^{\circledR}$ asépticos de $5 \mathrm{ml}$. Los sueros resultantes se obtuvieron por centrifugación a $3000 \mathrm{rpm}$ x $10 \mathrm{~min}$, y fueron trasladados en refrigeración al Laboratorio de Microbiología de la Facultad de Medicina Veterinaria, Universidad Nacional Mayor de San Marcos (FMV-UNMSM), Lima, donde se almacenaron a $-20{ }^{\circ} \mathrm{C}$ hasta su procesamiento. 
Las muestras se analizaron mediante la Prueba de Aglutinación Microscópica (MAT), considerada como prueba de referencia para leptospirosis por la OIE. Se empleó una batería con los cuatro serovares de Leptospira más representativos en el país (canicola, pomona, icterohaemorrhagiae, hardjo). Los sueros fueron considerados positivos cuando presentaron una aglutinación igual o mayor al $50 \%$ en la observación al microscopio de campo oscuro a por lo menos un serovar (dilución 1:100). Se repitió la prueba en los casos de sueros sospechosos (aglutinación de 25\%).

La seroprevalencia fue calculada en base a la fórmula de Ahlbom y Norell (1992), y expresada en porcentaje. Se empleó la prueba de Chi Cuadrado de Mantel y Hanszel (Armitage y Berry, 1997) para evaluar si había un factor de confusión debido a la edad de los animales, encontrando que no fue significativo.

La seroprevalencia de Leptospira sp. en la población bajo evaluación fue de $2.6 \%$ (3/116); siendo de $1.3 \%$ en el INIA y $5.3 \%$ en la ganadería de Mañazo. Los tres sueros reactores fueron positivos a Leptospira icterohaemorrhagiae con un título de 1:200 en los animales de Mañazo y de 1:100 en el animal del INIA. Los animales afectados tenían entre 3 y 4 años. El efecto del sexo no fue evaluado debido a que solo hubo tres machos en la población muestreada.

La baja seroprevalencia encontrada se encuentra afectada por la época del año. Las bajas temperaturas afectan la supervivencia de la Leptospira, aunque hay estudios que demuestran que pueden sobrevivir a temperaturas de $-20{ }^{\circ} \mathrm{C}$ por 100 días (Aguinaga et al., 2000) y mantener su vitalidad por varios días a temperaturas de refrigeración (Erosa, 2001). Asimismo, un estudio realizado en el altiplano peruano en la época seca encontró prevalencias de 1.1 a 1.6\% (Herrera et al., 2000). Por otro lado, el nivel de anticuerpos séricos disminuye a niveles no detectables en animales que no están infectados persistentemente (Radostits et al., 2002). Es posible, además, que existan hospedadores crónicos y la prueba de MAT no puede reconocer los anticuerpos de respuesta.

Existió contacto con animales de otras especies en las dos localidades. Los roedores silvestres podrían haber servido para diseminar la enfermedad, ya que ellos son reservorios del serovar icterohaemorrhagiae. Rivera (2007) reportó una seroprevalencia de $88.5 \%$ a este serovar en alpacas de Puno en la época seca y Cachata (2006) reportó el 100\% de bovinos afectados por el serovar icterohaemorrhagiae en bovinos de Puno en la época de lluvias. Asimismo, Sepúlveda et al. (2002) destacan la importancia que tienen los roedores y canes domésticos en la diseminación de la enfermedad en ganaderías bovinas. Cabe resaltar que no se encontraron serorreactores al serovar hardjo, considerando que el bovino es el reservorio de mantenimiento.

\section{Literatura Citada}

1. Aguinaga A, Mesalina A, Minaya $P$, Del Aguila R, Falcón E, Reyes $N$. 2000. Leptospirosis. Oficina General de Epidemiología - INS. [Internet], [20 abril 2006]. Disponible en: http:// www.oge.sld.pe/documentostecnicos/ leptospirosis.pdf

2. Ahlbom A, Norell S. 1992. Fundamentos de epidemiología. $3^{\text {a }}$ ed. Madrid: Ed Siglo XXI. 169 p.

3. Armitage P, Berry G. 1997. Estadística para investigación biomédica. $3^{\circ}$ ed. Barcelona: Harcourt Brace. 593 p.

4. Cachata S. 2006. Prevalencia de la leptospirosis bovina en dos distritos de la provincia de Puno-Puno. Tesis de Médico Veterinario. Lima: Facultad de Medicina Veterinaria, Univ Nacional Mayor de San Marcos. 50 p. 
5. Erosa A. 2001. Estructura genética y fisiología del género Leptospira. Rev Biomed 12: 282-287.

6. Faine S. 1994. Leptospira and leptospirosis. Florida, USA: SRC Press. $353 \mathrm{p}$.

7. Herrera J, Vasconcellos $S$, Morais $Z$, Ferreira F, Sakamoto S, Ferreira J, Pinheiro S. 2000. Soropositividade para leptospirose em alpacas criadas no altiplano peruano. Puno, Peru. Análise de associação com o índice pluviométrico. Arq Instituto Biológico São Paulo 67(2): 171-176.

8. Liceras de Hidalgo J. 1982. Avances en el diagnóstico de la leptospirosis. Bol Inst Nac Salud, Lima 3(2): 64-65.

9. Maulloux M. 1975. Leptospirosis = zoonosis. Int J Zoonoses 2: 45-54.

10. Ministerio de Salud. 2000. Leptospirosis. Módulos Técnicos. Serie Documentos Monográficos $\mathrm{N}^{\circ}$ 2. Lima: Ministerio de Salud, Oficina de Epidemiología. $56 \mathrm{p}$.

11. Miranda F. 1998. Selección de gramíneas forrajeras precoces y resistentes a heladas. Instituto Nacional de Investigación Agraria - INIA. [Internet],
[20 noviembre 2005]. Disponible en: http:/ www.visionveterinaria.com/articulos/ 17.htm

12. OIE. 2004. Manual para el diagnóstico de la leptospirosis. [Internet], [20 noviembre 2005]. Disponible en: http://int/ eng/normes/mmanual/A_00041.html

13. Radostits $O$, Gay C, Blood D, Hinchcliff K. 2002. Medicina Veterinaria, tratado de las enfermedades del ganado bovino, ovino, porcino, caprino y equino. Vol I. $9^{a}$ ed. España: McGrawHill Interamericana. $1206 \mathrm{p}$.

14. Rivera Z. 2007. Prevalencia de leptospirosis en alpacas de la Estación Experimental de Maranganí-IVITA, Cusco y su asociación con la época del año y sexo. Tesis de Médico Veterinario. Lima: Facultad de Medicina Veterinaria, Univ Nacional Mayor de San Marcos. 53 p.

15. Sepúlveda A, Santiago J, Preciado P. 2002. La rata y el perro, importantes vectores de la leptospirosis en explotaciones pecuarias de Cd. Guzmán, Jalisco. Rev Cub Med Trop 54(1): 21-23.

16. Vinetz JM. 2001. Leptospirosis. Curr Infect Dis 14: 527-538. 